\title{
Decision styles in judgments of applicant suitability
}

\author{
ALLEN J. SCHUH \\ California State University, Hayward, California
}

\begin{abstract}
Students $(N=112)$ rank-ordered the suitability of three applicants for a graduate teaching assistantship position. Six rank-order combinations were possible, each indicating a different decision style. Contrary to expectations, groups in high- and low-conflict conditions preferred (51\%) the applicant who had the highest lowest (Maximin or Wald decision strategy) score among the criterion categories.
\end{abstract}

When Webster (1982) surveyed the literature on interviewer judgment and decision making from over the past several decades of research, he concluded that actual and simulated employment interviews can be described by several judgment and decision-making models. Some findings-those of most professionals and some part-time evaluators-can be accounted for with a conflict model (Janis \& Mann, 1977), but one of the several cognitive information processing models-Bayesian, correlational, or variance analysis (Slovic \& Lichtenstein, 1971)describes the decisions of most part-time interviewers and almost all laboratory experiments better. Decisions are sometimes reached so quickly, however, that a feeling or affect model (Zajonc, 1980) must be used to account for some results, because of the lack of time to weigh the evidence carefully. Before Webster, the availability of different descriptive models had not been recognized, and this accounts for many apparently conflicting findings.

Judgment and decision-making style refers to the general influences on information gathering, clarification, combination, and prediction. Such a style exists within the architecture of a person's previously developed concepts, which are present in some quantitative amount and linked logically into what is referred to as a logical-mathematical structure. Synonyms for logical-mathematical structure in the literature (Henderson \& Nutt, 1980; Kilmann \& Mitroff, 1976; Ramaprasad \& Mitroff, 1984) include mental models, knowledge structures, cognitive maps, scripts, frames, and schemata. A logical-mathematical structure may consist of a very simple, naive cause-effect model or a very complex, well-developed theory. An interviewer's logical-mathematical structure will determine what factors and relationships he or she observes (Piaget, 1974; Posner \& McLeod, 1982; Ramaprasad, 1987). The different judgment and decision-making styles would form the basis for different judgments about criterion importance (Kilmann \& Herden, 1976).

Correspondence may be addressed to Allen J. Schuh, Department of Management and Finance, California State University, Hayward, CA 94542-3069.
Judgment and decision-making style is reflected in selection decisions, which include an estimate of the criterion environment (Agee, Taylor, \& Torgersen, 1976; Bierman, Bonini, \& Hausman, 1986; Eppen \& Gould, 1984; Markland, 1983). The principle of insufficient reason (the LaPlace strategy) assigns equal value to each criterion. The largest simple sum across criterion categories indicates the best applicant for the position. The Maximin criterion (the Wald strategy) assumes the worst will happen. If the decision maker is concerned with minimizing the maximum potential failure, the smallest score anywhere on the criterion categories for the applicants is found and the applicant with the largest lowest score is selected. The Maximax method (complete optimism) assumes that the very best outcome will occur. The decision maker selects the applicant with the largest standing on any criterion category. The Minimax Regret (the Savage strategy) requires a new opportunity-cost-payoff matrix (regret matrix) be established. The applicant that minimizes the maximum regret is chosen. The coefficient of optimality (the Hurwicz strategy) apportions the total criterion importance to the largest and smallest criterion standings for each applicant, while the other standings are ignored. The decision maker's judgment and decisionmaking style determines which criterion weighting he or she attends to, and in turn it is objectively illustrated by the final applicant rank-order that is made for the selection decision.

Does the judgment and decision-making style change when the interviewer is under pressure? If so, then decision makers under different levels of pressure should make different choices among applicants for a position. Webster (1982) pointed out that the presence or absence of stress was the most important variable that differentiated interviewers. The nonrational factor of feelings intruded and distorted evaluations when something personal was at stake.

Research needs to be done on the question of whether an interviewer who has something at stake (i.e., who is working under the conflict model) tends to choose a pessimistic strategy such as the Maximin or Minimax Regret, whereas those who are only offering a recommendation 
and have nothing directly at stake might choose one of the other strategies such as the LaPlace. Such a hypothesis seems to follow from the literature ( $\mathrm{O}^{\prime}$ Neill \& Eisner, 1981; Rozelle \& Baxter, 1981; Webster, 1982).

\section{METHOD}

\section{Participants}

The participants were 112 students in three sections of a class taught by the author.

\section{Decision Demands}

Students are frequently directed by a graduate teaching assistant, whose responsibilities include instruction, running group exercises, supervising students during computer exercises, answering student's questions, and giving and scoring tests.

\section{Procedure}

Students in three sections were provided the same information about three applicants for the teaching assistant position. Under the experimental condition, students in two of the sections (Ns of 46 and 33) were told that they were going to get a teaching assistant, but in the control condition $(N=33)$, the students were only to recommend a selection that would affect the other students but not themselves.

\section{Definitions}

Definitions of effectiveness criteria were given:

Instructional competence-Is the candidate clear and understandable in explanations; do lectures go smoothly; does the candidate follow a logical sequence of thought; is the candidate well prepared; does the candidate follow an outline; does the candidate interpret abstract ideas and theories clearly?

Instructor attitude-Does the candidate answer all questions (or admit if he or she doesn't know the answer), encourage questions during the lecture, enunciate well, make reasonable demands on student time, treat students as adults, have a sympathetic attitude toward students?

Interest-Does the candidate present material not in the reading assignments, encourage student interest in the material, keep subject matter interesting, stimulate student intellectual curiosity, help broaden students' interests?

\section{General Instructions}

The following general instructions were given:

You are to recommend the selection for a Graduate Teaching Assistant position. Rank-order the three applicants who are listed in the table shown. (In the table, applicant $A$ had scores on the criteria of 5, 4, and 4, respectively. Applicant B had scores of 1,7 , and 6. Applicant C had scores of 2, 2, and 8.) Scores represent effectiveness ratings where 1 is lowest and 9 is highest standing on the criterion. Your task is to rankorder your choices. Assign a rank of " 1 " to your first choice. Give your second choice a rank of " 2 ." The applicant you consider least qualified you should give a rank of " 3 ." Which of these applicants should be given a chance to be a Graduate Teaching Assistant for this course, and during this academic term?

\section{RESULTS}

Data were accumulated by experimental condition and summarized in a two-way table according to applicant rank-order. The possible rank-orders represented different judgment and decision-making styles: $\mathrm{ABC}$, a Wald variant; BAC, LaPlace and Savage; CBA, Maximax; $A C B$, Wald; $C A B$, Hurwicz; and BCA, which fit no known general strategy.

The two experimental groups were not significantly different $\left[\chi^{2}(2)=1.03\right.$, n.s. $]$, and the pooled experimental group was not different from the control group $\left[\chi^{2}(2)=\right.$
4.16, n.s.]. Cells with small frequencies were combined according to established procedures.

Frequencies across the six alternative combinations were significantly different $\left[\chi^{2}(5)=125.31, p<.001\right.$, $C=.726$ ]. The combination ACB (standard Maximin Wald) was selected by $51.7 \%$ of the students. The second highest selection (26.7\%) was ABC, which is a Wald variant. Clearly, students adopted a risk-adverse strategy when it came to selecting a teaching assistant, even when it was not for themselves.

The LaPlace and Savage alternative was slected by $7.1 \%$, Maximax by $8 \%$, and Hurwicz by $3.5 \%$; BCA was selected by $2.6 \%$.

\section{DISCUSSION}

Webster's (1982) conclusion about the availability of different judgment and decision-making styles was verified by this research, in that all six possible combinations of applicant order were selected by at least some of the evaluators.

Webster's (1982) other conclusion, that the presence or absence of stress differentiated decision makers, was not verified. The experimental group was expected to adopt a risk-adverse strategy within their logical-mathematical structure and this should thus have been reflected in their evaluation of the criterion components. The control group was expected to make a decision that would reflect highly rational components within their logical-mathematical structures and to adopt a criterionevaluation strategy such as the LaPlace. Such was not the case. Both groups were risk adverse. The largest number of decision makers selected the applicant order with the applicant who had the highest lowest (Maximin) criterion score first. The second most frequent order of applicant selection was like the first in that the applicant who had the highest lowest criterion score was selected, but the order of the next two candidates was reversed. The dominance of negative information had been shown in other research (Constantin, 1976; Crissy \& Regan, 1951; Springbett, 1958). The results of this study are similar to those suggested by Shaw (1972), who showed that selection choices were confined to examination of applicants' low standing on criterion categories. Lowest standing relative to other applicants on a criterion leads to a low overall suitability evaluation, while other standings are discounted.

The present study calls into question the flexibility of decision style within the logical-mathematical structure. The group of students who would have to live with their decision and the group that was only making recommendations for the other sections of the class both adopted the same judgment and decision-making style. One must question, then, the conclusion of Webster (1982) that decison makers carry with them several different judgment and decision-making strategies within their logical-mathematical structure and that the strategies shift in response to levels of decision pressure. These results suggest there may be less latitude for shifting among strategies than was thought.

Significant decision improvement requires the development of more adequate explanations of the role of judgment and decision-making style in decision making.

\section{REFERENCES}

Agee, M. H., TAylor, R. E., \& Torgersen, P. E. (1976). Quantitative analysis for management decisions. Englewood Cliffs, NJ: Prentice-Hall.

Bierman, H., Bonini, C. P., \& Hausman, W. H. (1986). Quantitative analysis for business decisions. Homewood, IL: Irwin.

Constantin, S. W. (1976). An investigation of information favorability in the employment interview. Journal of Applied Psychology, 61, 743-749.

Crissy, W. J. E., \& Regan, J. J. (1951). Halo in the employment interview. Journal of Applied Psychology, 35, 338-341.

EPPEN, G. D., \& GouLD, F. J. (1984). Introductory management science. Englewood Cliffs, NJ: Prentice-Hall. 
Henderson, J. C., \& NutT, P. C. (1980). The influence of decision styles on decision making behavior. Management Science, 26, 371-386.

JANIS, I. L., \& MANN, L. (1977). Decision making: A psychological analysis of conflict, choice, and commitment. New York: The Free Press.

Kilmann, R. H., \& Herden, R. P. (1976). Toward a systematic methodology for evaluating the impact of interventions on organizational effectiveness. Academy of Management Review, 1, 87-98.

KILMANN, R. H., \& MITROFF, I. I. (1976). Qualitative versus quantitative analysis for management science: Different forms for different psychological types. Interfaces, 6, 17-27.

MarKLAND, R. E. (1983). Topics in management science. New York: Wiley.

O'NeILl, P., \& EISNER, M. (1981). Responsibility and decision making: Factors that contribute to careful attention in a choice task. Canadian Journal of Behavioral Science, 13, 288-296.

Piaget, J. (1974). Understanding causality. New York: W. W. Norton.

PoSNER, M. I., \& MCLEOD, P. (1982). Information processing models: In search of elemenary operations. Annual Review of Psychology, 33, 477-514.

RAmAPRASAD, A. (1987). Cognitive process as a basis for MIS and DSS design. Management Science, 33, 139-148.
RAMAPrASAD, A., \& MitrofF, I. I. (1984). On formulating strategic problems. Academy of Management Review, 9, 597-605.

Rozelle, R. M., \& BAXTER, J. C. (1981). Influence of role pressures on the perceiver: Judgments of videotaped interviews varying judge accountability and responsibility. Journal of Applied Psychology, 66, 437-441.

SHAw, E. A. (1972). Differential impact of negative stereotyping in employee selection. Personnel Psychology, 25, 333-338.

Slovic, P. \& Lichtenstein, S. (1971). Comparison of Bayesian and regression approaches to the study of information processing in judgment. Organizational Behavior \& Human Performance, 6, 649-744.

SPRINGBETT, B. M. (1958). Factors affecting the final decison in the employment interview. Canadian Journal of Psychology, 12, 13-22.

WEBSTER, E. C. (1982). The employment interview: A social judgment process. Schomberg, ON, Canada: S. I. P. Publications.

ZaJonc, R. B. (1980). Feeling and thinking: Preferences need no inferences. American Psychologist, 35, 151-175.

(Manuscript received June 11, 1989.) 